\title{
Pressurized Operation of a Planar Solid Oxide Cell Stack
}

\author{
Jensen, Søren Højgaard; Sun, Xiufu; Ebbesen, Sune Dalgaard; Chen, Ming
}

Published in:

Fuel Cells

Link to article, DOI:

10.1002/fuce.201500180

Publication date:

2016

Document Version

Peer reviewed version

Link back to DTU Orbit

Citation (APA):

Jensen, S. H., Sun, X., Ebbesen, S. D., \& Chen, M. (2016). Pressurized Operation of a Planar Solid Oxide Cell Stack. Fuel Cells, 16(2), 205-218. https://doi.org/10.1002/fuce.201500180

\section{General rights}

Copyright and moral rights for the publications made accessible in the public portal are retained by the authors and/or other copyright owners and it is a condition of accessing publications that users recognise and abide by the legal requirements associated with these rights.

- Users may download and print one copy of any publication from the public portal for the purpose of private study or research.

- You may not further distribute the material or use it for any profit-making activity or commercial gain

- You may freely distribute the URL identifying the publication in the public portal

If you believe that this document breaches copyright please contact us providing details, and we will remove access to the work immediately and investigate your claim. 
This is the peer reviewed version of the following article: Jensen, S. H., Sun, X., Ebbesen, S. D. and Chen, M. (2016), Pressurized Operation of a Planar Solid Oxide Cell Stack. Fuel Cells, 16: 205-218. doi:10.1002/fuce.201500180 which has been published in final form

http://onlinelibrary.wiley.com/doi/10.1002/fuce.201500180/abstract. This article may be used for non-commercial purposes in accordance with Wiley Terms and Conditions for Self-Archiving. 


\title{
Pressurized Operation of a Planar Solid Oxide Cell Stack
}

\author{
S. H. Jensen ${ }^{1 *}$, X. Sun ${ }^{1}$, S. D. Ebbesen ${ }^{1}$, M. Chen ${ }^{1}$ \\ ${ }^{1}$ Department of Energy Conversion and Storage, Technical University of Denmark, Roskilde, Denmark. \\ Corresponding author [*] shjj@dtu.dk
}

\begin{abstract}
:
Solid oxide cells (SOCs) can be operated either as fuel cells (SOFC) to convert fuels to electricity or as electrolysers (SOEC) to convert electricity to fuels such as hydrogen or methane. Pressurized operation of SOCs provide several benefits on both cell and system level. If successfully matured, pressurized SOEC based electrolysers can become more efficient both energy- and cost-wise than PEM and Alkaline systems. Pressurization of SOFCs can significantly increase the cell power density and reduce the size of auxiliary components.

In the present study, a SOC stack was successfully operated at pressures up to 25 bar. The pressure dependency of the measured current-voltage (iV) curves and impedance spectra on the SOC stack are analysed and the relation between various system parameters and pressure is derived. With increasing pressure the open circuit voltage (OCV) and the reaction kinetics (electrode performance) increases for thermodynamic and kinetic reasons, respectively. Further, the summit frequency of the gas concentration impedance arc and the pressure difference across the stack and heat exchangers is seen to decrease with increasing pressure following a power-law expression. Finally a durability test was conducted at 10 bar.
\end{abstract}

\section{Keywords:}

Durability, Electrochemical Impedance Spectroscopy, iV-curves, Planar, Pressure, Solid Oxide Cell, Stack

\section{Introduction:}

The widespread use of fossil fuels within the current energy infrastructure is considered as one of the largest sources of $\mathrm{CO}_{2}$ emissions, which is argued to cause global warming and climate changes. One of the top energy priorities is therefore exploring environmentally friendly alternatives to fossil fuels (e.g. wind or solar) and thereby reduce $\mathrm{CO}_{2}$ emissions. [1-5] Renewable energy technologies are sometimes criticised for not providing the necessary security of supply because the production cannot be tuned to fit the consumers' needs. Thus, it is necessary to store energy by e.g. converting surplus electricity to chemical energy in the form of compounds such as hydrogen. Hydrogen offers significant promise as a basis for a future energy technology, and is argued to be the most versatile, efficient and environmentally friendly fuel, although handling of 
hydrogen may be problematic. Hydrogen produced by electrolysis, even at higher production prices, may be implemented in certain markets due to the high purity of the produced hydrogen.

Steam electrolysis in Solid Oxide Cells (SOC) for hydrogen production was under development during the early 1980s[5-7] and has again become increasingly investigated during recent years as a green energy technology. Mainly single cells have been tested for electrolysis performance and durability, and only a relatively limited number of studies focusing on the performance and durability of high temperature electrolysis stacks have been conducted.[5] In general the stacks are found both to perform worse and also to degrade faster than single cells.[5] In contrast to this, some stacks from Topsoe Fuel Cell (TOFC) [8-10] and Ceramatec[11] has shown similar durability as single cells[12] and button cells[13] when operated at low current densities (below an electrolysis current density of $1 \mathrm{~A} \mathrm{~cm}^{-2}$ ). Pressurised operation of the SOEC stack is energetically favoured and expected to increase the efficiency by 3 to $5 \% .[14,15]$ Although several research institutes have shown the effect of pressurisation when operating solid oxide cells as fuel cells, examination of the performance of SOECs at increased pressure has only recently been initiated.[16-21] A significant decrease of approximately $20 \%$ in the internal resistance in both fuel cell and electrolysis cell mode of a Ni-YSZ based cell (Ni-YSZ|YSZ|LSM-YSZ) was found by increasing the pressure from 1 to 10 atm, when operated with $50 \% \mathrm{H}_{2} \mathrm{O}-50 \% \mathrm{H}_{2}$ supplied to the Ni-YSZelectrode and $\mathrm{O}_{2}$ supplied to the LSM-YSZ-electrode.[16] This decrease in cell resistance is caused by the increase with pressure of the frequency of reactants hitting the triple phase boundary and subsequently converting to products, $[22,23]$ as well as decreased diffusion resistance. $[17,18]$ The open circuit voltage was found to increase with increasing pressure as predicted by the Nernst equation. The same gain in performance is observed in electrolysis mode as compared to fuel cell mode (equal decrease in ASR as a function of pressure), but this is obscured by the observed increase in OCV.[19] Although the internal resistance of the cell was found to decrease the overall performance of the cell (operating cell voltage) was close to unchanged due to the increase in the open circuit voltage (OCV).[16] Similar trends were found in a recently published examination of the overall performance for two different SOECs as function of pressure ranging from 1-10 bar and at cell voltages from $1 \mathrm{~V}$ to $1.3 \mathrm{~V}$.[20] Further, at stack level a similar decrease in the internal resistance of $20 \%$ was observed for a 10 -cell stack when increasing the pressure from 1 bar to 6.9 bar.[17] The specific cell type was not stated in the publication. For this stack test the short term durability was also examined, in which the stack voltage increased around $5 \%$ for the first 60 hours (corresponding to an increase of around $80 \%$ per 1000 hours of operation). Hereafter the stack voltage decreased, indicating cell damage; indeed some cracked cells and broken seals were observed after test.[17]

In this study we present iV curves and impedance spectra recorded with an 11-cell planar stack at pressures ranging from 1 bar up to 25 bar. The internal resistance and the OCV obtained from the measured iV curves correlates with the above mentioned trends, however the leak rate is observed to increase with increasing pressure. The stack impedance recorded at elevated pressure correlates with the internal resistance obtained from the iV curves and resembles the trends previously observed on single cells.[16] Interestingly, the pressure difference across the stack and 
heat exchangers decreases with increasing pressure suggesting a partially isentropic pressure drop. Finally a 200 hour durability test was conducted at 10 bar.

\section{Experimental}

\subsection{Stack Description:}

The stack used in this test was produced by Haldor Topsoe A/S (Denmark). It contains 11 cells, each with an active area of $87.7 \mathrm{~cm}^{2}$. The anode supported cells (ASC) consist of a nickel-yttria stabilized zirconia cermet as the hydrogen electrode, yttria stabilized zirconia as the electrolyte, lanthanum strontium cobalt ferrite oxide mixed with ceria gadolinium oxide as the oxygen electrode and ceria gadolinium oxide as a barrier layer between the oxygen electrode and the electrolyte. The individual cells in the stack are connected by coated Crofer interconnects forming a single repeat unit (SRU). The 11 SRUs are stacked between two endplates that act as current terminals. The gas is supplied from the endplates to the electrode compartments by internal manifolding in the cells and interconnects. Glass seals are used to prevent gas mixing between electrode compartments and surroundings. Pressure is not expected to affect the sealings since the stack was pressurized both inside and outside using passive pressure balancing as described below. However the gas diffusion in the porous support layer under the seals increases with increasing pressure. Further stack information is given elsewhere.[10]

\subsection{Test Setup:}

Fig. 1A show a photo of the high pressure SOC stack test system. The left hand side of the photo shows a pressure vessel which accommodates a furnace, stack housing and manifold, heat exchangers (HEX), $\mathrm{H}_{2} \mathrm{O}$ evaporator, condensation flasks, probes etc. Feed-trough's mounted on flanges (red arrows) provides access for gas tubing, power lines and data acquisition cables to the furnace, SOC stack, sensors and gas handling equipment inside the pressure vessel. The right part of the photo shows the gas handling cabinet which houses equipment such as mass flow controllers (MFC), differential pressure sensors (DPS), reduction valves and pressure controlling systems. The safety of the system is monitored and controlled by a programmable logic controller (PLC) located in a drawer below the gas/pressure handling cabinet. Power-electronics to operate the stack in either fuel cell mode or electrolysis mode is placed below the drawer with the PLC.

The gas handling concept is shown schematically in Fig. 1B. The MFCs in the figure is labelled from a to $g$. $\mathrm{N}_{2}$ was used as sweep gas (with a flow rate of $300 \mathrm{I} \mathrm{h}^{-1}$ through $\mathrm{MFC}_{\mathrm{f}}$ ) in the entire experiment. This was done to avoid potential leaks in the stack, gas piping or auxiliary components to cause accumulation of hydrogen or oxygen inside the vessel. A pressure sensor (not shown in Fig. 1B) measures the pressure inside the pressure vessel. The pressure in the vessel is controlled by controlling the flow rate of $\mathrm{N}_{2}$ through $\mathrm{MFC}_{b}$ via a PID loop which takes the measured pressure as input and the $\mathrm{MFC}_{\mathrm{b}}$ flowrate set point as output. In order to balance the pressure between the

\footnotetext{
${ }^{i}$ Here we refer to the cells as SOFC cells, i.e. that the cells are supported the negative hydrogen electrodes.
} 
two electrode compartments of the SOEC stack against the pressure in the pressure vessel, the electrode compartment exhaust gas pipes are open towards the autoclave (In Fig. 1B shown as small open-ended pipes near the condensers). This ensures practically the same pressure in the pressure vessel as in the electrode compartments. In order to avoid $\mathrm{O}_{2}$ and $\mathrm{H}_{2}$ accumulation in the pressure vessel, the $\mathrm{MFC}_{\mathrm{e}}$ and $\mathrm{MFC}_{\mathrm{g}}$ set points were automatically controlled to ensure a small flow of $\mathrm{N}_{2}$ from the pressure vessel into the fuel and air gas streams. When the SOC stack operates as an electrolyser or fuel cell it generates or consumes $\mathrm{H}_{2}$ at the negative electrodes and $\mathrm{O}_{2}$ at the positive electrodes. The $\mathrm{MFC}_{\mathrm{e}}$ and $\mathrm{MFC}_{\mathrm{g}}$ set points were automatically adjusted to compensate for these changes to maintain the small flows of $\mathrm{N}_{2}$ from the vessel into the $\mathrm{H}_{2} / \mathrm{H}_{2} \mathrm{O}$ and air gas streams.

The $\mathrm{O}_{2}$ concentration in the pressure vessel was monitored by a sensor (not shown in Fig. 1B). A small amount of $\mathrm{O}_{2}$ was maintained in the pressure vessel to burn off any $\mathrm{H}_{2}$ leaking from the fuel electrode compartment, auxiliary components and gas pipes. The $\mathrm{O}_{2}$ concentration in the pressure vessel was controlled by a PID loop which has the $\mathrm{O}_{2}$ concentration as input and the flow rate set point of $\mathrm{MFC}_{\mathrm{e}}$ as output.

The inlet and outlet pressure before and after the two heat exchangers were measured against the pressure in the autoclave with four APR-2000ALW differential pressure sensors (DPS), each with a measurement range of 0 to $500 \mathrm{mbar} \pm 0.5 \mathrm{mbar}$. The pressure of the entering/exiting gas streams was measured on the cold side of the heat exchangers, just before the gasses entered/exited the HEX. The DPS's were placed outside the pressure vessel, but for simplicity the extra piping was not included in Fig. 1B. Since there is no flow in the pipes to the sensors the measurement accuracy is not affected by this. Vacuum pumps (not shown in the figure) were used to suck out the gas from $\mathrm{MFC}_{\mathrm{e}}, \mathrm{MFC}_{\mathrm{f}}$ and $\mathrm{MFC}_{\mathrm{g}}$, to ensure the stack can be operated at ambient pressure. However, since the condensers cannot be emptied at ambient pressure, the lowest pressure used in this article was 1.2 bar. Here the pressure unit "bar" refers to bar-absolute, which means in this paper 1.2 bar, i.e. 0.2 bar above atmospheric (i.e. ambient or gauge) pressure.

Although the test setup is designed for operation up to 45-50 bar, the furnace power was not configured for full power and hence it was insufficient to maintain the stack temperature above 25 bar. For this reason the stack performance was investigated from 1.2 bar to 25 bar.

The furnace temperature was measured $\sim 1 \mathrm{~mm}$ above the stack and controlled by the furnace controller. The stack temperature was measured with a temperature probe placed inside a $\sim 10$ $\mathrm{mm}$ deep hole in the stack bottom plate.

\subsection{Startup Procedure:}

At start up, first the stack was reduced at $850{ }^{\circ} \mathrm{C}$ with a mixture of $\mathrm{H}_{2}$ and $\mathrm{N}_{2}$ supplied to the fuel electrode compartment. The temperature was then lowered to $750{ }^{\circ} \mathrm{C}$ for performance characterization at various pressures. During controlled pressure changes, the pressure ramp rate was kept below 1 bar $\mathrm{h}^{-1}$ and the pressure differences between the pressure vessel and two electrode compartments were below \pm 50 mbar. 


\subsection{Stack iV and Impedance Measurements:}

The stack performance was characterized with DC polarization (iV) curves and impedance spectroscopy. The iV curves and impedance measurements were recorded with $400 \mathrm{I} \mathrm{h} \mathrm{h}^{-1} 50 \% \mathrm{H}_{2}+$ $50 \% \mathrm{H}_{2} \mathrm{O}$ supplied to the negative electrodes ( $\mathrm{Ni}-\mathrm{YSZ}$ ) and $400 \mathrm{I} \mathrm{h}^{-1}$ air to the positive electrodes (LSCF-CGO). The total electrode area in the stack was $965 \mathrm{~cm}^{2}$, which gives an area specific flow rate of $0.41 \mathrm{I} \cdot \mathrm{h}^{-1} \cdot \mathrm{cm}^{-2}$. The $\mathrm{H}_{2}$ and $\mathrm{O}_{2}$ (in the air supply) utilization at maximum current density $\left(0.25 \mathrm{~A} \mathrm{~cm}^{-2}\right)$ in fuel cell direction was $46 \%$ and $54 \%$, respectively. The $\mathrm{H}_{2} \mathrm{O}$ utilization at maximum current density in electrolysis mode $\left(-0.25 \mathrm{~A} \mathrm{~cm}^{-2}\right)$ was also $46 \%$. During iV curve acquisitions in SOFC and SOEC mode, a current step of $\sim 0.01 \mathrm{~A} \mathrm{~cm}^{-2}$ was applied. Each step lasted $\sim 50$ seconds while the voltage of the entire stack and each cell was measured.

The stack impedance was measured from $25 \mathrm{kHz}$ to $0.1 \mathrm{~Hz}$ with normal single sine wave impedance spectroscopy using a Solartron 1260 in combination with an external shunt and a voltage bias compensation system. A Kepco BOP 50-4M was used to boost the $16 \mathrm{~mA}$ AC current from the Solartron to 1 Ampere $A C$ i.e. with an $A C$ current density of $\sim 0.01 \mathrm{~A} \mathrm{~cm}^{-2}$. The measurement system is described further detail elsewhere.[24] From the iV curves, the area specific resistance (ASR) of the individual cells within the stack was found to be $\sim 0.5 \Omega \mathrm{cm}^{-2}$. This means the voltage vibration amplitude used to record the impedance spectra was $\sim 5 \mathrm{mV}$ on the individual cells such that a linear relationship between current and polarization voltage can be assumed.

\section{Result:}

\subsection{Initial Performance Characterisation:}

Fig. 2A shows the difference between the pressure of the inlet gas before it enters the heat exchanger (HEX) and the pressure of the outlet gas after it exits the HEX, i.e. the differential pressure across the stack and the HEX (see Fig. 1B). The differential pressure is measured using the differential pressure sensors (DPS's). More specific, at e.g. the fuel gas side it is measured as the differential pressure measured by DPS $\alpha$ minus the differential pressure measured by DPS ${ }_{\beta}$, assuming that the pressure in the vessel is the same at all places inside the vessel. The differential pressure on the air-side is measured in a similar way. It is seen that the differential pressure across the stack and HEX decreases with increasing pressure. Above 10 bar, accurate measurements were prohibited by fluctuations in the differential pressure. The fluctuations were observed on both air and fuel side. The fluctuation at the fuel side was possibly due to condensation/evaporation of $\mathrm{H}_{2} \mathrm{O}$ inside the HEX. The fluctuations at the air side were mainly observed on the HEX inlet side (DPS $\alpha$, Fig. 1B) and were possibly caused by pressure-induced flow-instabilities in $\mathrm{MFC}_{\mathrm{a}}$. The error bars in the figure are taken as the DPS measurements uncertainty of 0.5 mbar. Power-law fits to the data are given in the figure. Note that the exponent for both fits deviates from one.

In Fig. 2B the temperature of the gas inside the pressure vessel is shown as a function of gas pressure inside the vessel. A linear model is seen to provide a good fit to the temperature data. 
Further, the temperature in the stack is shown in the figure. The stack temperature is also fitted with a linear model which shows the temperature increases slightly with pressure. The temperature inside both the stack and the pressure vessel fluctuated a few degrees. This is most likely due to variations in the gas flows inside the stack and pressure vessel, respectively for which reason error bars of $\pm 2{ }^{\circ} \mathrm{C}$ were used in Fig. $2 \mathrm{~B}$.

Stack iV curves at pressure from 1.2 to 25 bar are shown in Fig. 3. The stack voltage was observed to fluctuate at pressures above 3 bar. The $\mathrm{H}_{2} \mathrm{O}$ evaporation temperature increases with increasing pressure which most likely explains this behaviour; above 3 bar $\mathrm{H}_{2} \mathrm{O}$ evaporation/condensation occurred outside the evaporator and condenser which caused variations in the $\mathrm{H}_{2} \mathrm{O}$ flow, thus affecting $\mathrm{H}_{2} / \mathrm{H}_{2} \mathrm{O}$ ratio at the cells and thus the Nernst voltage and in turn the stack voltage.

From linear fits to the iV curves in Fig. 3, OCV (i.e. the stack voltage at $0 \mathrm{~A} \mathrm{~cm}^{-2}$ ) was obtained. $\mathrm{OCV}_{\mathrm{m}}$ vs. pressure is shown in Fig. $4 \mathrm{~A}$. At $50 \% \mathrm{H}_{2} / 50 \% \mathrm{H}_{2} \mathrm{O}$, the $\mathrm{ASR}$ in fuel cell $(\mathrm{FC}$ ) mode is known to be slightly smaller than the ASR in electrolysis (EL) mode. [25] Unfortunately linear fits applied to either $\mathrm{FC}$ or EL data provided inaccurate $\mathrm{OCV}_{\mathrm{m}}$ values due to the voltage fluctuations and instead $\mathrm{OCV}_{m}$ was obtained from linear fit applied to the combined FC + EL data.

The theoretical OCV, $\mathrm{OCV}_{\text {th }}$ can be determined from the Nernst equation which expresses the negative cell voltage:

$$
E=E_{o}-\frac{R T}{n F} \ln \left(\frac{P_{H_{2}} \cdot P_{O_{2}}^{1 / 2}}{P_{o}^{1 / 2} \cdot P_{H_{2} \mathrm{O}}}\right)
$$

where $E_{o}$ is the standard potential, $R$ the ideal gas constant, $T$ is the temperature in Kelvin, $n$ the number of electrons involved in the reaction $\mathrm{H}_{2} \mathrm{O} \rightarrow 1 / 2 \mathrm{O}_{2}+\mathrm{H}_{2}, F$ is Faradays constant, $P_{o}$ is the standard pressure, and $P$ is the partial pressure of the respective reactants and products. Thus for the stack, $\mathrm{OCV}_{\mathrm{th}}=-11 \cdot E$, since the stack have 11 cells in series. From equation (1) it is seen that $\mathrm{OCV}_{\text {th }}$ is linear with respect to the logarithm of the stack pressure and that the slope is $\frac{11}{2} \cdot \frac{R T}{n F}=$ $0.24 \mathrm{~V}$. OCV $\mathrm{Oth}_{\text {th }}$ is shown with a thick black line in the figure and a linear fit to $\mathrm{OCV}_{\mathrm{m}} \mathrm{vs}$. log pressure is shown with a thin black line. Expressions for $\mathrm{OCV}_{\mathrm{th}}$ and the fit to $\mathrm{OCV}_{\mathrm{m}}$ is shown in the figure. Within the estimated uncertainty on $\mathrm{OCV}_{\mathrm{m}}$, except for the measurement at 5 bar, $\mathrm{OCV}$ is seen to increase linearly with the logarithm of the pressure, however with a slope of $0.20 \mathrm{~V}$, a bit less than the theoretical slope of $0.24 \mathrm{~V}$. Based on the linear fits, $\mathrm{OCV}_{\mathrm{m}}$ is estimated to $10.45 \mathrm{~V}$ at 1 bar, i.e. reasonably close to $\mathrm{OCV}_{\text {th }}$ which is calculated to be $10.52 \mathrm{~V}$.

In between some of the iV curve measurements, the gas at the fuel electrodes was switched to dry $\mathrm{H}_{2}$ with $\mathrm{N}_{2}$ (with flow rates ranging from $100 \mathrm{I} \mathrm{h}^{-1}$ to $450 \mathrm{I} \mathrm{h}^{-1}$ ). By measuring the stack OCV the average $\mathrm{H}_{2} \mathrm{O}$ concentration could be calculated from the Nernst equation. Multiplying the $\mathrm{H}_{2} \mathrm{O}$ concentration with the $\mathrm{H}_{2}$ flow rate an estimate of the leak rate was obtained as presented in Fig. $4 B$. 
The slope of the iV curves in Fig. 3 is seen to decrease with increasing pressure, indicating that the internal resistance of the stack decreases with increasing pressure. From the linear fits to the iV curves, the slope was obtained. The average cell area specific resistance (ASR) is calculated as the slope of the iV curve fits divided by the number of cells in the stack and the cell electrode area. The average cell ASR vs. pressure is shown in Fig. 4C. A power-law fit was applied to the data points and the expression for the fit is shown in the figure. The stack ASR sums both the resistance of pressure-dependent electrode reactions and pressure independent electrolyte resistances and thus a power law model cannot be expected to provide a perfect fit to the stack ASR. However, due to the limited pressure range and accuracy of the measured ASR, a more advanced model would imply undesired high uncertainties on the model values. For this reason a simple power-law expression was chosen to model the ASR.

Stack impedance spectra recorded at $750{ }^{\circ} \mathrm{C}$ at various gas compositions are presented in Fig. $5 \mathrm{~A}$. The spectra are corrected for $11 \mu \mathrm{H}$ wiring inductance. The obtained impedance was divided with the number of cells (11) and multiplied with the cell-electrode active area to obtain the Area Specific Impedance (ASI) expressed in $\Omega \mathrm{cm}^{2}$. The inset in Fig. $5 \mathrm{~A}$ shows a Nyquist plot of the same impedance spectra.

Two difference plots of some of the spectra shown in Fig. 5A are shown in Fig. 5B. The green spectrum shows the difference between the imaginary parts of the impedance data recorded with $\mathrm{O}_{2}$ and air at the air-electrode while having $50 \% \mathrm{H}_{2}+50 \% \mathrm{H}_{2} \mathrm{O}$ at the fuel-electrode and the black spectrum shows the difference between the imaginary parts of the impedance data recorded with $50 \% \mathrm{H}_{2}+50 \% \mathrm{H}_{2} \mathrm{O}$ and $75 \% \mathrm{H}_{2}+25 \% \mathrm{H}_{2} \mathrm{O}$ at the fuel-electrode while having $\mathrm{O}_{2}$ at the air-electrode.

Impedance spectra recorded at pressure ranging from 1.2 to 25 bar is shown in Fig. 5C. A Nyquist plot of the same spectra is shown in the inset Fig. 5C. Two large arcs are observed. The size of the high-frequency arc is seen to decrease with increasing pressure whereas the size of the lowfrequency is less dependent of pressure. From the Bode-plot in Fig. 5C, the characteristic frequency of the low frequency arc is seen to decrease with increasing pressure. Selected difference spectra are shown in Fig. 5D. The inset shows a magnification of the high-frequency part of the difference spectra and illustrates how the high-frequency arc with summit frequency around $10 \mathrm{kHz}$ decreases with increasing pressure.

\subsection{Durability:}

After measuring the iV curves shown in Fig. 3, leak measurements in Fig. 4B, and the impedance spectra shown in Fig. 5, the pressure was set to 10 bar and a long-term test was initiated. The temperature was kept at $750{ }^{\circ} \mathrm{C}$. The gas flow rates were $200 \mathrm{I} \mathrm{h} \mathrm{h}^{-1} \mathrm{H}_{2}+200 \mathrm{I} \mathrm{h} \mathrm{h}^{-1} \mathrm{H}_{2} \mathrm{O}$ and $400 \mathrm{I} \mathrm{h}$ air, and the current density was initially $-0.25 \mathrm{~A} \mathrm{~cm}^{-2}$, but later reduced to $-0.18 \mathrm{~A} \mathrm{~cm}^{-2}$. The stack voltage as a function of time is seen in Fig. 6A. OCV and ASR, measured from linear fits to cell iV curves (measured simultaneously with the stack iV curves as those shown in Fig. 3 and fitted in the same manner) are shown in Fig. 6B.

After 60 hours of operation, the safety system triggered, causing a pressure and temperature drop which lasted 29 hours. 29 hours after the triggering event, the gas flows were re-enabled, the 
furnace temperature ramped up to $750^{\circ} \mathrm{C}$ at $2{ }^{\circ} \mathrm{C}$ per minute and the pressure increased to 10 bar. After this, iV curves were measured. The ASR and OCV is shown in Fig. 6B. The OCV was observed to be the same as before the $\sim 60$ electrolysis operation. The ASR increased in average $5 \%$ relative to the ASR before the onset of the durability test. Possibly the air electrodes were partially reduced by the triggering event which could explain the increase in ASR.

After the measurement of the iV curves, the durability test was resumed. Unfortunately after 35 hours the steam generation system began to cause problems: A malfunctioning of a water pressure stabilization system gradually escalated over the next 38 hours causing increasingly severe stops in the steam supply. The power supply had a maximum voltage of $20 \mathrm{~V}$, so due to steam starvation the stack voltage several times during these 38 hours, specifically during the last 5 hours, went up to $19 \mathrm{~V}$.

After the steam-starvation, the pressure stabilization system was repaired and the steam supply re-enabled. Before the durability test was resumed, iV curves were measured. The OCV and ASR are shown in Fig. 6B. The OCV is seen to be similar to the previous OCV measurements for all cells, but the ASR has drastically increased, in particular for the cells with highest number corresponding to the cells farthest away from the gas inlet.

After recording iV-curves the durability test was resumed, however at a lower current density of $0.18 \mathrm{~A} \mathrm{~cm}^{-2}$ to keep the individual cell voltages within a safe operation window. At $165 \mathrm{~h}$ a short controlled service of the $\mathrm{H}_{2} \mathrm{O}$ pressure fluctuation damper was conducted to ensure continued stable operation of the steam supply system. The stack voltage after resuming electrolysis operation is comparable with the stack voltage before the service, which means - as expected the service event did not affect the stack performance. Unfortunately just before the durability test reached $200 \mathrm{~h}$, the stack experienced steam starvation again. This time, it was because the safety system triggered due to a control-logic issue. Unfortunately one of the cells cracked due to this last steam-starvation event and the durability test couldn't be continued.

\section{Discussion:}

\subsection{Differential Pressure:}

In Fig. $2 \mathrm{~A}$, the pressure across the heat exchanger and stack is seen to decrease with increasing pressure. Based on HEX manufacturer calculations the pressure drop across the HEX is estimated to be less than $20 \%$ of the total pressure drop. The exponents obtained from power-law fits to the data were -0.74 and -0.85 for the air and fuel side, respectively. As described in detail in the Appendix, an isentropic pressure drop across the HEX's and stack can be expressed as

$$
d P=K P^{-\gamma^{-1}}
$$

where $K$ is a pressure independent constant and where $\gamma$ is the ratio of specific heats of the gas

(i.e. $C_{p} C_{v}^{-1}$ ). Since $\gamma_{\mathrm{Air}} \cong \gamma_{\mathrm{H}_{2}} \cong 1.4$ and $\gamma_{\mathrm{H}_{2} \mathrm{O}} \cong 1.3$ at relevant operating conditions[26] we obtain $-\gamma_{\text {Air }}^{-1}=-0.71$ and, assuming linearity, for $50 \% \mathrm{H}_{2}+50 \% \mathrm{H}_{2} \mathrm{O},-\gamma_{\mathrm{H}_{2}+\mathrm{H}_{2} \mathrm{O}}^{-1}=-0.75$. The values should 
be compared with the experimentally found values presented above, i.e. -0.74 and -0.85 for the air and fuel side, respectively. The experimentally found values are closer to -1 than the theoretical values possibly because the assumption of an isentropic pressure drop is not satisfied for the HEX where the gas experience extensive heat exchange during the passage. However, since the pressure drop across the stack is estimated to be more than four times greater than the pressure drop across the HEX, this could explain why the pressure drop across stack + HEX exhibit quasi isentropic behaviour.

The decrease in the differential pressure with increasing pressure can help relaxing the constraints on the dimensions of the gas-channels inside the stack which could potentially open up for new designs with higher contact areas between the various layers in the stack, thereby decreasing the ASR and degradation issues due to interconnect/cell contact loss.

\subsection{Vessel Temperature vs. Pressure:}

The pressure vessel is water cooled, which means the surface temperature of the inner walls in the pressure vessel can be assumed to be fairly independent of temperature. Thus, the linear increase in the temperature of the gas inside the pressure vessel is related to increasing heat dissipation from the furnace with increasing pressure. This also explains why the furnace couldn't maintain the stack-temperature above 25 bar, i.e. the heat dissipation above 25 bar exceeded the furnace power.

Fans circulate the $\mathrm{N}_{2}$ inside the pressure vessel. This is to ensure no hot-spots develop which could compromise the mechanical strength of the vessel and pose a safety issue.

Convective heat transfer of $\mathrm{N}_{2}$ was recently studied with heat exchangers in the pressure range from $5-30$ bar and gas temperatures up to $300{ }^{\circ} \mathrm{C}$.[27] The $\mathrm{N}_{2}$ heat transfer coefficient (with the dimension $\mathrm{W} \mathrm{m}^{-2} \mathrm{~K}^{-1}$ ) exhibited a quasilinear increase as function of the gas pressure, i.e. similar to the trend observed in Fig. 2B. Yang et al.[27] ascribed the pressure-dependency of the heat transfer coefficient to be dominated by the pressure-dependent change in the gas density. They observed a $200 \%$ increase in the convective heat transfer coefficient when increasing the pressure from 5 bar to 30 bar.

Using the expression shown in Fig. 2B for the temperature inside the vessel, the temperature at 30 bar is estimated to be $110{ }^{\circ} \mathrm{C}$. At 5 bar, it was measured to be $54^{\circ} \mathrm{C}$. The autoclave cooling water temperature was around $22{ }^{\circ} \mathrm{C}$ which gives a temperature rise of $\left(110^{\circ} \mathrm{C}-22^{\circ} \mathrm{C}\right)\left(54^{\circ} \mathrm{C}-22^{\circ} \mathrm{C}\right)^{-1}=2.75$ i.e. a relative temperature increase of $175 \%$, which is in reasonable agreement with the pressure dependency of the heat transfer coefficient reported by Yang et al.[27]. Further, the furnace insulation is about $10 \mathrm{~cm}$ thick, so radiation heat dissipation can be neglected and thus the furnace heat dissipation is supposed to be dominated by convection. 


\subsection{OCV vs. Pressure:}

$\mathrm{OCV}_{m}$ was seen in to increase quasi-linearly with the logarithm of the pressure, but with a smaller slope than the theoretical slope. From the linear fit a slope of $0.20 \mathrm{~V}$ (Fig. 4A) was obtained i.e. less than the theoretical slope of $0.24 \mathrm{~V}$. The slope of $0.20 \mathrm{~V}$ (and $0.24 \mathrm{~V}$ theoretically) for the stack is equivalent to a slope of $18 \mathrm{mV}$ (and $22 \mathrm{mV}$ theoretically) per cell. At 1 bar, the difference between $O C V_{\text {th }}$ and the linear fit to $O C V_{m}$ was $10.52 \mathrm{~V}-10.45 \mathrm{~V}=70 \mathrm{mV}$, i.e. $6.4 \mathrm{mV}$ per cell.

In a previous test conducted by some of the same authors on a similar cell to the ones used in the tested stack, also with $50 \% \mathrm{H}_{2}+50 \% \mathrm{H}_{2} \mathrm{O}$ to the fuel electrode but operated at $800^{\circ} \mathrm{C}$ and with $\mathrm{O}_{2}$ to the air electrode and gas pressures ranging from 1-15 bar, $\mathrm{OCV}_{\mathrm{th}}-\mathrm{OCV}_{\mathrm{m}}$ was only $0.6 \mathrm{mV}$ at 1 bar and the pressure dependency slope was $22.3 \mathrm{mV}$ i.e. close to the theoretical slope of $23.0 \mathrm{mV}$.[19]

Further, in another test on a similar cell conducted by some of the authors, also with $50 \% \mathrm{H}_{2}+$ $50 \% \mathrm{H}_{2} \mathrm{O}$ to the fuel electrode and at $750{ }^{\circ} \mathrm{C}$ but with $\mathrm{O}_{2}$ to the air electrode, and with pressures ranging from 0.4-10 bar, $\mathrm{OCV}_{\text {th }}-\mathrm{OCV}_{\mathrm{m}}$ was as large as $9 \mathrm{mV}$ at $1 \mathrm{bar}$, and the pressure dependency slope was $16.5 \mathrm{mV}$ i.e. deviating substantially from the theoretical slope of $22.0 \mathrm{mV}$.[16]

The difference between $\mathrm{OCV}_{\text {th }}$ and $\mathrm{OCV}_{\mathrm{m}}$ measured at ambient pressure vs. the difference between the pressure-dependency-slopes obtained in this work and reported previously[16, 19] is presented in Fig. 7. The values are fitted using a straight line crossing $(0,0)$.

Fig. 7 shows that $O C V_{\text {th }}-O C V_{m}$ at 1 bar is more or less proportional to the difference between the observed and theoretical OCV pressure dependency slope. This provides interesting information about the type of leak. Electronic leak would be pressure-independent i.e. it does not contribute to difference between the observed and theoretical OCV pressure dependency slope. Specifically, a purely electronic leak will be placed on the vertical line crossing the $x$-axis at $0 \mathrm{mV}$ in Fig. 7 . This is in agreement with previous findings by Rasmussen et al. where electronic leak was estimated to contribute with less than $2 \%$ of the total leak. [28] Instead Rasmussen et al. found that electrolyte pin-holes and gas leaks at the glass seals were the main leak-contributors. It should be noted that the cell test geometry used by Rasmussen et al. differs from the geometry of the tested stack. Specifically the size of the cell area relative to the seal area is different. Rasmussen et al. used a cell with $16 \mathrm{~cm}^{2}$ electrode area. In contrast the electrode area of the cells used in the stack was $87.7 \mathrm{~cm}^{2}$. Note however that the internal manifolding in the stack increases the seal area.

If the leaks were controlled by binary gas diffusion through electrolyte pin-holes and through the porous layers at the seals, the oxygen flux from the air-electrodes to the fuel-electrodes would be pressure independent. Likewise the hydrogen flux from the fuel-electrodes to the air-electrodes would be pressure independent. This means leaks due to binary gas diffusion processes would also be placed on the vertical line crossing the $x$-axis at $0 \mathrm{mV}$ in Fig. 7. In contrast to electronic leaks and binary gas diffusion leaks, Knudsen diffusion of $\mathrm{O}_{2}$ from the air-electrode to the fuel electrode, and of $\mathrm{H}_{2}$ in the reverse direction through electrolyte pin-holes and through the porous layers at the seals surrounding the internal manifolding will increase with increasing pressure. 
Finally, both $\mathrm{OCV}_{\mathrm{th}}-\mathrm{OCV}_{\mathrm{m}}$ at 1 bar and the difference between the observed and theoretical OCV pressure dependency slope scales with the amount of electrolyte pin-holes and the size of the gas leak through the layers at the seals surrounding the internal manifolding, i.e. it can explain the linear dependency observed in Fig. 7. For this reason data presented in Fig. 7 indicate that the leak is affected by Knudsen diffusion.

Importantly, Knudsen diffusion of $\mathrm{O}_{2}$ from the air-electrode to the fuel electrode is proportional to $P$, which means Knudsen diffusion would imply non-linear behaviour of $O C V_{m}$ vs. $\log (P)$ in Fig. $4 A$. With increasing pressure the total diffusion becomes dominated by binary diffusion since the mean-free path for binary diffusion is proportional to $P^{-1}$ whereas the mean free path for Knudsen diffusion is pressure independent. Such a partial shift from Knudsen diffusion to binary diffusion could explain the quasi-linear relation between $\mathrm{OCV}_{\mathrm{m}}$ vs. $\log (\mathrm{P})$ (Fig. 4A) while observing the difference between the observed and theoretical OCV pressure dependency slope.

Although errors in the flow-rate (e.g. due to poor calibration of the MFC's) have least impact on $\mathrm{OCV}_{\mathrm{m}}$ at $50 \% \mathrm{H}_{2}+50 \% \mathrm{H}_{2} \mathrm{O}$ (since at these concentrations the slope of the Nernst equation is smallest), it should be noted that deviations between the flow rate reported by the MFC and the actual flow rate could change $\mathrm{OCV}_{\text {th }}$ thus affecting the observations shown in the figure. However if the flow-rate errors are constant during the pressure variation experiments the error will only affect the vertical position of the data points in Fig. 7, i.e. the flow-rate error will not move the $x$ axis position.

Inserting $\mathrm{OCV}_{\mathrm{m}} / 11$ in the Nernst equation (1) an estimate for the actual $\mathrm{H}_{2}$ and $\mathrm{H}_{2} \mathrm{O}$ ratio at the fuel electrodes and thus the $\mathrm{H}_{2} \mathrm{O}$ leak rate can be obtained. At 20 bar this leak rate is almost eight times higher than the leak rate observed with the $\mathrm{H}_{2}+\mathrm{N}_{2}$ supply (Fig. 4B) i.e. clearly indicating problems with the MFC calibration which was possibly related to the poor stability of the steam supply.

Both Fig. 4A and Fig. 4B shows that the leak rate increases with increasing pressure indicating that part load operation of the stack could be unattractively inefficient at high pressure unless leak rates are further decreased by e.g. improved sealing and/or thicker electrolytes.

\subsection{ASR vs. Pressure:}

The ASR was seen to decrease with increasing pressure in Fig. $4 \mathrm{C}$ and the same trend was observed by impedance spectroscopy in Fig. $5 \mathrm{C}$ and the inset therein. The same trend has been observed previously on stacks, single cells and electrodes.[16, 17, 19, 23, 29] A small increase in the ASR is seen from 20 bar to 25 bar. This is most likely caused by a slightly lower stack temperature at 25 bar than at 20 bar (Fig. 2B) because the furnace couldn't provide enough heat to maintain the stack-temperature at $750^{\circ} \mathrm{C}$ above 25 bar.

However, it should be noted that due to the gas leak (which increases with pressure), the temperature inside the stack will be higher than that of the environment. Since the stack 
temperature was measured in a hole in the stack bottom plate, the temperature increase in the core of the stack due to the leak is not known and therefore not further discussed in this paper.

\subsection{Impedance vs. Pressure:}

The peak around 1-2 Hz in Fig. 5A is seen to be affected by the gas composition at both electrodes which is also illustrated by the gas-shift-peaks in Fig. 5B. The peaks and the related low-frequency arc in the inset in Fig. 5A is usually attributed to gas conversion at the fuel electrode.[30] However, in a plug-flow geometry gas diffusion and conversion is known to be coupled[25, 31, 32] and rather than speaking of either diffusion or conversion, one should refer to the term gas concentration impedance.[33] The coupling is sometimes observed as an increased conversion resistance with increasing diffusion resistance due to the altered gas composition at the active electrode.[25] Further, it is important to distinguish between Knudsen gas diffusion and binary gas diffusion in the fuel electrode support layer. A comprehensive analytic description involving the dusty gas model have recently been provided by Fu et al.[34] Obviously, when the spectra are recorded with oxygen to the air-electrode binary gas diffusion doesn't contribute to the impedance of that electrode. When air is supplied to the air-electrode both binary gas diffusion and Knudsen gas diffusion will contribute to the impedance, although on hydrogen electrode supported single cells the contribution from air-electrode is expected to be small compared to the contribution from the fuel-electrode.[18, 34] On single cells, switching from air to oxygen have been shown to affect distribution of relaxation-time (DRT) deconvolutions of impedance spectra at around $10 \mathrm{~Hz}$.[35] Due to the difference in geometry between single cells and stacks this could possibly be the same process that affects the stack impedance at a characteristic frequency around $1-2 \mathrm{~Hz}$.

Further, a peak around $600 \mathrm{~Hz}$ is seen in the difference spectra in Fig. 5B when shifting from air to $\mathrm{O}_{2}$. The related electrochemical reaction is known to be sensitive to the oxygen partial pressure [35-37] and has previously been ascribed to dissociative adsorption/desorption of $\mathrm{O}_{2}$ combined with electrochemical reduction/oxidation and transfer of oxygen species at the TPB.[23, 38] It was not possible to see from the difference spectra in Fig. 5D whether the oxygen-electrode process at $600 \mathrm{~Hz}$ was affected by pressure, but it is assumed that the related resistance also decreases with increasing pressure, as observed in previous pressurized electrode experiments.[23, 29]

The difference spectrum in Fig. 5B for the shift in the $\mathrm{H}_{2} \mathrm{O}$ composition has a peak around $6 \mathrm{kHz}$ in agreement with previous observations on Ni-YSZ-electrodes.[35-37] The related process has been proposed to be charge transfer between $\mathrm{YSZ}$ and $\mathrm{Ni}$ and diffusion of charged species at the TPB. $[39,40]$ The spectra in Fig. 5C and the difference spectra in Fig. 5D show that the size of the 6 $\mathrm{kHz}$ arc decreases with increasing pressure.

The spectra in Fig. 5C and the inset therein show that the size of the gas concentration arc is close to be unaffected by pressure in agreement with previous findings.[16, 19] Further, the summit frequency of the gas concentration arc shifts to lower frequency with increasing pressure. Based on the ideal gas law, a $P^{-1}$-depencency of the summit frequency of the gas conversion arc is previously predicted for the fuel electrode.[30] A similar continuous stirred-tank reactor (CSTR)- 
model would predict a $P^{-1}$-depencency for the summit frequency of the oxygen (in air) conversion arc at the air-electrode. The resistance related to gas conversion and binary gas diffusion is predicted to be independent of pressure.[30, 41]

Although several individual processes could be resolved in Fig. 5, modelling of the impedance data (in particular the high-frequency part of the impedance) with a high-fidelity equivalent circuit was not possible due to the considerable inductance and uncertainty in determining the ohmic resistance.

However, from a rough batch fitting of the spectra in Fig. 5A, the stack inductance and the average ohmic resistance was estimated to $11 \mu \mathrm{H}$ and $0.24 \Omega \mathrm{cm}^{2}$, respectively. A more reliable impedance measurement at similar operating conditions (but only at ambient pressure) on a stack with similar foot print, cell and IC type, but with different positioning of the current rods and voltage probes provided much more reliable high-frequency data and in turn improved precision in the estimation of the ohmic resistance which was estimated to be $0.26 \Omega \mathrm{cm}^{2}$.[42]

Instead of modelling the full spectra, the low-frequency gas concentration arc was modelled with an (RC)-circuit. Here only the low-frequency part of $Z^{\prime \prime}$ (Fig. 5A) with values below $-0.016 \Omega \mathrm{cm}^{2}$ was modelled. The spectra were fitted individually, i.e. the data was not batch fitted. The resistance and summit frequency

$$
f_{s}=\frac{1}{2 \pi} \cdot \frac{1}{R C}
$$

is shown in Fig. 8A. In equation (3) $R$ is the area specific resistance and $C$ is the area specific capacity. The resistance data was fitted with a power-law expression and the exponent was 0.04 . The size of the gas concentration resistance was found to be $0.13 \Omega \mathrm{cm}^{2}$ at 1 bar. The positive exponent of 0.04 deviates from the expected pressure-independency of gas conversion[30] and binary gas diffusion.[41] The increase in gas concentration resistance with increasing pressure from 1 to 25 bar is most likely caused by the improved electrode performance with increasing pressure. This is because the increased electrode performance increases the local current density near the gas inlet while decreasing the local current density near the gas outlet, as described in detail elsewhere.[32] This shifts the gas concentration impedance away from "Plug-flow" behaviour towards "CSTR" behaviour, $[32,43,44]$ noting that the size of "CSTR" resistance is twice that of "Plug-flow" resistance.[44]

The summit frequency data in Fig. $8 \mathrm{~A}$ was also fitted with a power-law expression. The obtained exponent of -0.90 deviates from the a pressure dependency of -1 which would be expected from simple gas conversion CSRT considerations.[30] Momma et al. investigated button cells at pressures ranging from 0.1 to 10 bar[18] and noted that "The time constant calculated from low frequency arc is exactly proportional to pressure at high pressure region, although it became rather saturated at lowest pressure presumably because of the effect of diffusion in porous media", and later that "Under de-pressurized conditions, Knudsen diffusion became predominant as compared to molecular diffusion". A coupling between gas conversion in the gas channels and Knudsen gas diffusion in the porous support layer and electrode could explain why the exponent 
derived in this work deviates from -1. This is because for normal operation conditions, the diffusion process is known to have a summit frequency about a decade higher than the gas conversion process, such that when Knudsen diffusion become important at the lowest pressure, the relative size of the diffusion resistance to the conversion resistance increases, thereby shifting the summit frequency for the combined gas concentration impedance to higher frequencies, thus counter-acting the decreasing summit-frequency of the gas conversion process. In other words, when the diffusion process resistance increases (with decreasing pressure, at the lowest pressures where Knudsen diffusion become important) it will increase the characteristic frequency of the coupled gas concentration (gas conversion + gas diffusion) arc, thus moving the pressure dependency of the gas concentration arc from the expected -1 (with gas conversion + binary gas diffusion) towards the observed -0.9.

The pressure dependence of the electrode reactions (the size of the high-frequency arcs on both the fuel-electrode and the air-electrode) can be estimated the following way. The sum of the resistances of the mid- and high-frequency arcs can be estimated as the average cell ASR obtained from the iV curves in Fig. 3 minus the series resistance $\left(0.24 \Omega \mathrm{cm}^{2}\right)$ and gas concentration resistance $\left(0.13 \Omega \mathrm{cm}^{2}\right)$ obtained from impedance spectra fitting above. Here we ignore the small pressure dependency of the size of the gas concentration impedance observed in Fig. 8A. The data is plotted in Fig. 8B. The exponent of the power-law fit is -0.31 . It has previously been observed that charge transfer limited reactions involving dissociative adsorbed oxygen at low coverage on composite LSM/YSZ-electrodes exhibit a -0.25 exponent[23]. The total pressure dependency of an LSM/YSZ electrode was recently reported to exhibit a -0.17 exponent dependency[29]. A - 0.27 exponent behaviour have been found for the $\mathrm{P}_{\mathrm{H} 2 \mathrm{O}}$ dependence for Ni-YSZ electrodes.[45] The observed power-law dependency of -0.31 for the electrode ASR seem to correlate reasonably well with these observations. A possible reason for the slightly higher dependency in this study might be caused by the general temperature increase in the stack with pressure (Fig. 2B). This is supported by the fact that the resistance in Fig. $8 \mathrm{~B}$ increases slightly when the pressure increases from 20 bar to 25 bar which correlates with the small temperature decrease when going from 20 bar to 25 bar (Fig. 2B).

\subsection{Durability test at 10 bar:}

The stack voltage as function of time at constant-current electrolysis operation at 10 bar is shown in Fig. 6. The stack voltage fluctuations are due to the $\mathrm{H}_{2} \mathrm{O}$ flow-instabilities caused by the poor control of $\mathrm{H}_{2} \mathrm{O}$ evaporation/condensation at 10 bar. No gas cleaning[46] was applied to the gasses before they were led to the stack.

After $\sim 60$ hours of operation, the oxygen content inside the pressure vessel increased above $2.3 \%$ which triggered the safety system. Consequently the safety system shut off the stack current, opened a safety valve which vented the pressure vessel, set the gas flow on MFC $\mathrm{C}_{\mathrm{a}}, \mathrm{MFC}_{\mathrm{c}}$ and $\mathrm{MFC}_{\mathrm{d}}$ to $0 \mathrm{I} \mathrm{h}^{-1}$, and at the same time cut the power to the furnace (Fig. 1B). This caused the furnace temperature to drop to $100{ }^{\circ} \mathrm{C}$ within 20 hours and the pressure to drop from 10 bar to 1 bar within 4 minutes. The vacuum pumps placed downstream of $\mathrm{MFC}_{\mathrm{e}}, \mathrm{MFC}_{\mathrm{f}}$ and $\mathrm{MFC}_{\mathrm{g}}$ further reduced the pressure to $\sim 0.2$ bar over the next $\sim 20$ minutes. This condition lasted for the next 29 
hours. During the 29 hours a small $12 \mathrm{I} \mathrm{h}^{-1} \mathrm{H}_{2}$ flow through $\mathrm{MFC}_{\mathrm{b}}$ kept the fuel electrode reduced. 29 hours after the triggering event, the gas flows were re-enabled, the furnace temperature ramped up to $750{ }^{\circ} \mathrm{C}$ at $2{ }^{\circ} \mathrm{C}$ per minute and the pressure increased to 10 bar. After this, iV curves were measured.

The OCV was observed to be the same as before the $\sim 60 \mathrm{~h}$ electrolysis operation and triggering event and only an average ASR increase of $5 \%$ was observed, indicating that no cells cracked due to the event. This is possibly because the $\mathrm{Ni}$ in the fuel electrodes was kept reduced during the pressure and temperature drop event by the small $12 \mathrm{I} \mathrm{h}^{-1} \mathrm{H}_{2}$ flow. In contrast to this, the steam starvation occurring after $\sim 95 \mathrm{~h}$ electrolysis operation caused a dramatic ASR increase in particular in the cells farthest away from the gas inlet (those with high cell number). This is possibly because the YSZ in the electrolyte and fuel electrodes got damaged by the high cathodic over-potential. (The stack voltage went up to $19 \mathrm{~V}$ which is equal to $1.7 \mathrm{~V}$ in average per cell).

Within the $\sim 200$ h durability test shown in Fig. 6 the degradation rates seem to be in the order of 1 to $3 \mathrm{~V} \mathrm{kh}^{-1}$. Although the degradation rates seem to decrease with time, it should be stressed that the relatively short durability of the test and the several interruptions within the $\sim 200 \mathrm{~h}$ operation pose a high uncertainty on the measured degradation rates. Also, a decrease in current density generally decreases the degradation rate. However the decrease in current density after $\sim 95 \mathrm{~h}$ electrolysis operation was accompanied by an increase in the polarisation voltage due to the increased $A S R$, and degradation rates tend to increase with increasing polarisation voltage.

In short it is not known from the presented pressurized electrolysis test whether the initial degradation decreases after the first few hundred hours of operation, although ambient stack tests indicate this: Investigations with a similar HTAS stack operated at ambient pressure and 850 ${ }^{\circ} \mathrm{C}$ exhibited degradation rates which levelled off after the first $500 \mathrm{~h}$ of operation to around $0.04 \mathrm{~V}$ $\mathrm{kh}^{-1}$ per cell corresponding to $\sim 0.44 \mathrm{~V} \mathrm{kh}^{-1}$ degradation for an 11-cell.[8]. On cell-level initial degradation or temporal passivation lasting several hundred hours of the Ni-YSZ-electrode operated in $\mathrm{H}_{2}-\mathrm{H}_{2} \mathrm{O}$ mixtures have previously been observed and was related to gas phase impurities including $\mathrm{Si}$ species blocking the triple phase boundaries (TPB).[47-49]

The evaporater (Fig. 1B) was supplied with reverse osmosis water. Although the water is evaporated before it is sent to the stack it is believed that some impurities would be carried with the gas which could cause degradation of the Ni-YSZ TPBs. Another impurity source is the $\mathrm{H}_{2}$ gas. Gas purification have previous been demonstrated to significantly decrease the electrode degradation.[46, 49] but was not applied in this test. Gas purification does not remove degradation by $\mathrm{Cr}$-species from the interconnects (ICs).[50] Depending on the mechanism, deposition of impurities can be increased with increasing pressure. Increased mobility of $\mathrm{Ni}$ or higher IC corrosion rates due to the higher steam-partial pressure could also be present.

\section{Conclusion}

A planar 11-cell solid oxide stack was characterized in both fuel cell mode and electrolysis mode at elevated pressure from 1.2 bar to 25 bar with $50 \% \mathrm{H}_{2}+50 \% \mathrm{H}_{2} \mathrm{O}$ to the Ni-YSZ-electrodes and air 
to the LSCF-CGO electrodes. Subsequently the stack was long-term tested as a steam electrolyser for 200 hours at 10 bar. The main conclusions from the stack operation were:

- The differential pressure across the stack and heat exchangers (HEX's) decreases with increasing pressure following a power-law relation. The power-law exponent was -0.85 for $50 \% \mathrm{H}_{2}+50 \% \mathrm{H}_{2} \mathrm{O}$ and -0.74 for air indicating a partially isentropic pressure-drop across the stack.

- The furnace heat dissipation increases linearly with pressure suggesting that the heat dissipation from the furnace to the interior of the pressure vessel is dominated by convection.

- The measured OCV increases quasi-linearly with the logarithm of the pressure in the investigated pressure range. A systematic deviation of the pressure dependency between the theoretical and measured OCV was observed and compared with literature findings. The leak rate increase with increasing pressure is possibly related to competing Knudsen and Binary gas diffusion leaks through electrolyte pin-holes and through the porous layers at the seals. The increasing gas leak with increasing pressure could possibly make partial load operation of the stack less efficient and attractive at high pressure unless cells and seals optimized for highpressure operation, i.e. with decreased leak rates are used.

- From impedance measurements the resistance of the gas concentration arc was seen to follow a $P^{0.04}$ dependency and the summit frequency a $P^{-0.9}$ dependency. The resistance dependency of $P^{0.04}$ can possibly be explained by pressure-induced changes in the electrode current distribution. The summit frequency dependency of $P^{-0.9}$ deviates from $P^{-1}$ which is expected from the theory of gas conversion in the gas channels. Knudsen gas diffusion in the porous support layer and electrodes can possibly explain this deviation.

- As earlier reported in the open literature, the ASR was observed to decrease with increasing pressure. Subtracting the gas concentration resistance and the Ohmic resistance, the electrode resistance was found to follow a $P^{-0.31}$ dependency. The pressure dependency is slightly higher than what is previously reported. An observed trend of increasing stack temperature of a few degrees when increasing the pressure from 1.2 bar to 25 bar can most likely explain why the pressure dependency was slightly higher in the present study.

- The stack was operated as a steam-electrolyser for almost 200 hours. During the electrolysis operation the stack survived a pressure-and-temperature cycle. Contrary to this, steam starvation combined with a high average cell voltage around $1.7 \mathrm{~V}$ severely damaged the stack and eventually cracked one of the cells.

- The initial degradation rates for the 11-cell stack were around 1-3V $\mathrm{kh}^{-1}$. The degradation rate could possibly level off after some hundred hours which calls for stable long-term tests of SOEC stacks beyond $200 \mathrm{~h}$ operation.

\section{Acknowledgement:}

We would like to thank Haldor Topsoe A/S for supplying the tested stack. This work was financially supported by Energy Technology Development and Demonstration Programme (EUDP) under the Danish Energy Agency via the projects "E2P2H2" (grant no. 64013-0583) and "Green Natural Gas" 
(grant no. 64011-0036), and by Energinet.dk through the ForskEL project "Solid Oxide Cells for Grid Balancing" (Grant no 2013-1-12013).

\section{Appendix:}

The pressure across the heat exchangers (HEX's) and stack is seen to decrease with increasing pressure in Fig. 2A. Based on calculations from the HEX manufacturer, the pressure drop across the HEX is estimated to be less than 3 mbar when the stack is operated at 1 bar. This corresponds to $\sim 20 \%$ of the total pressure drop across the HEX and stack. For this reason the description below focusses on the conditions inside the stack. The exponents obtained from power-law fits to the data were -0.74 and -0.85 for the air and fuel side, respectively. Here we provide a theory describing the relation between the measured pressure drop and the gas pressure inside the pressure vessel. The theory is based on the Darcy-Forchheimer equation supported by experimental findings of gas pressure drop inside metal foam combined with the theory for an isentropic pressure drop in and ideal gas.

If the gas inside the stack has negligible heat exchange with the surroundings we can assume an isentropic pressure drop across the stack.

An isentropic pressure change in an ideal gas can be expressed as

$$
\left(\frac{P}{P_{0}}\right)^{\gamma^{-1}}=\frac{\rho}{\rho_{0}}
$$

where $P_{0}$ is a reference pressure, $\rho_{0}$ is the reference volumetric density, and $\gamma$ is the ratio of specific heats of the gas (i.e. $C_{p} C_{v}^{-1}$ ). Equation (4) can be rearranged to yield

$$
\rho=K_{1} \cdot P^{\gamma^{-1}}, K_{1}=\rho_{0}\left(P_{0}^{-1}\right)^{\gamma^{-1}}
$$

where $K_{l}$ is a pressure independent constant.

The relation

$$
\frac{\partial(\rho P)}{\partial z}=K_{2}
$$

where $\rho$ is the volumetric density of air, $P$ is the pressure, $z$ is the flow distance and $K_{2}$ is another pressure independent constant, was theoretically derived from the Darcy-Forchheimer equation, and experimentally verified in the pressure range 1-2.1 bar and air-flow range 5 to 26 $\mathrm{kg} \cdot \mathrm{m}^{-2} \cdot \mathrm{s}^{-1}$ with a metal foam with a $400 \mu \mathrm{m}$ pore size by Bonnet et al.[51]

Inserting equation (5) into equation (6) gives 


$$
\frac{\partial\left(P^{1+\gamma^{-1}}\right)}{\partial z}=K_{1} K_{2} \Rightarrow\left(1+\gamma^{-1}\right) P^{\gamma^{-1}} \cdot \frac{\partial P}{\partial z}=K_{1} K_{2} \Rightarrow \frac{\partial P}{\partial z}=K_{1} K_{2}\left(1+\gamma^{-1}\right)^{-1} P^{-\gamma^{-1}}
$$

Since the total length, $L$, of the gas flow through the stack (and HEX) doesn't change with pressure we can write the pressure difference between the inlet pressure $P_{1}$ and the outlet pressure $P_{2}$ as

$$
d P=L K_{1} K_{2}\left(1+\gamma^{-1}\right)^{-1} P^{-\gamma^{-1}}
$$

which is valid for small relative pressure changes $d P$ and constant molar gas flow rates.

The smallest gas-flow cross section in the stack is supposed to be inside the gas distributer layers in the stack. The average height of the flow cannels in the gas distributer layer is here estimated to $100 \mu \mathrm{m}$. The width of the layer is taken to be $10 \mathrm{~cm}$. With a $400 \mathrm{I} \mathrm{h}^{-1}$ (normal liter) air flow, this gives a flow rate of $14 \mathrm{~kg} \mathrm{~kg} \cdot \mathrm{m}^{-2} \cdot \mathrm{s}^{-1}$, i.e. well within the $5-26 \mathrm{~kg} \cdot \mathrm{m}^{-2} \cdot \mathrm{s}^{-1}$ flow-range investigated by Bonnet et al.[51] The larger pores/dimensions in the stack compared with the pores in the metal foam studied by Bonnet et al. does not affect the validity of equation (8).

Since $\gamma_{\mathrm{Air}} \cong \gamma_{\mathrm{H}_{2}} \cong 1.4$ and $\gamma_{\mathrm{H}_{2} \mathrm{O}} \cong 1.3$ at relevant operating conditions[26] we obtain $-\gamma_{\text {Air }}^{-1}=-0.71$ and, assuming linearity, for $50 \% \mathrm{H}_{2}+50 \% \mathrm{H}_{2} \mathrm{O},-\gamma_{\mathrm{H}_{2}+\mathrm{H}_{2} \mathrm{O}}^{-1}=-0.75$. These values should be compared with the experimentally obtained values, i.e. -0.74 and -0.85 for the air and fuel side, respectively. The experimentally found values are closer to -1 than the theoretical values possibly because the assumption of an isentropic pressure drop is not satisfied for the HEX.

\section{References:}

[1] H. Vendt, V. Plzak, Kerntechnik 1991, 56, 22.

[2] V. Utgikar, T. Thiesen, Int. J. Hydrogen Energy 2006, 31, 939.

[3] N. Osada, H. Uchida, M. Watanabe, J. Electrochem. Soc. 2006, 153, A816.

[4] R. Steeneveldt, B. Berger, T. A. Torp, Chem. Eng. Res. Des. 2006, 84, 739.

[5] S. D. Ebbesen, S. H. Jensen, A. Hauch, M. B. Mogensen, Chem. Rev. 2014, 114, 10697.

[6] W. Dönitz, R. Schmidberger, E. Steinheil, R. Streicher, Int. J. Hydrogen Energy 1980, 5, 55.

[7] A. O. Isenberg, Solid State lonics 1981, 3-4, 431.

[8] S. D. Ebbesen, J. Høgh, K. A. Nielsen, J. U. Nielsen, M. Mogensen, Int. J. Hydrogen Energy 2011, 36, 7363.

[9] J. Schefold, A. Brisse, M. Zahid, ECS Trans. 2010, 28, 357.

[10] M. Chen, J. V. T. Høgh, J. U. Nielsen, J. J. Bentzen, S. D. Ebbesen, P. V. Hendriksen, Fuel Cells 2013, 13, 638.

[11] X. Zhang, J. E. O'Brien, R. C. O'Brien, J. J. Hartvigsen, G. Tao, G. K. Housley, Int. J. Hydrogen Energy 2013, 38, 20.

[12] S. D. Ebbesen, C. Graves, A. Hauch, S. H. Jensen, M. Mogensen, J. Electrochem. Soc. 2010, 157, B1419. 
[13] X. Zhang, J. E. O'Brien, R. C. O'Brien, ASME $201210^{\text {th }}$ Int. Conf. on Fuel Cell Science, Engineering and Techn., San Diego, California, 2012, pp. 1.

[14] J. B. Hansen, N. Christiansen, J. U. Nielsen, ECS Trans. 2011, 35, 2941.

[15] C. V. Olshausen, D. Rüger, Proc. $10^{\text {th }}$ European SOFC forum, Luzern, Switzerland, 2012, pp. A0506.

[16] S. H. Jensen, X. Sun, S. D. Ebbesen, R. Knibbe, M. Mogensen, Int. J. Hydrogen Energy 2010, 35, 9544.

[17] J. E. O’Brien, X. Zhang, G. K. Housley, K. DeWall, L. Moore-McAteer, G. Tao, Idaho National Laboratory, Report No. 12-26891, Idaho Falls, Idaho. 2012.

[18] A. Momma, K. Takano, Y. Tanaka, T. Kato, A. Yamamoto, ECS Trans. 2013, 57, 699.

[19] X. Sun, A. D. Bonaccorso, C. Graves, S. D. Ebbesen, S. H. Jensen, A. Hagen, P. Holtappels, P. V. Hendriksen, M. B. Mogensen, Fuel Cells 2015, 15, 697.

[20] L. Bernadet, G. Gousseau, A. Chatroux, J. Laurencin, F. Mauvy, M. Reytier, Int. J. Hydrogen Energy 2015, 40, 12918.

[21] L. Bernadet, G. Gousseau, A. Chatroux, J. Laurencin, F. Mauvy, M. Reytier, ECS Trans. 2015, 68, 3369.

[22] R. Kikuchi, T. Yano, T. Takeguchi, K. Eguchi, Solid State lonics 2004, 174, 111.

[23] E. C. Thomsen, G. W. Coffey, L. R. Pederson, O. A. Marina, J. Power Sources 2009, 191, 217.

[24] S. H. Jensen, K. Engelbrecht, C. Bernuy-Lopez, J. Electrochem. Soc. 2012, 159,

[25] S. D. Ebbesen, X. Sun, M. B. Mogensen, Faraday Discuss. 2015,

[26] Gases - Specific Heats and Individual Gas Constants, can be found under http://www.engineeringtoolbox.com/specific-heat-capacity-gases-d 159.html, 2015.

[27] Z. Yang, Z. Zhao, Y. Liu, Y. Chang, Z. Cao, Exp. Therm. Fluid Sci. 2011, 35, 1427.

[28] J. F. B. Rasmussen, P. V. Hendriksen, A. Hagen, Fuel Cells 2008, 8, 385.

[29] G. Hughes, J. Railsback, D. Butts, S. A. Barnett, ECS Trans. 2015, 68, 687.

[30] S. Primdahl, M. Mogensen, J. Electrochem. Soc. 1998, 145, 2431.

[31] T. Jacobsen, P. V. Hendriksen, S. Koch, Electrochim. Acta 2008, 53, 7500.

[32] W. G. Bessler, S. Gewies, J. Electrochem. Soc. 2007, 154, B548.

[33] W. G. Bessler, J. Electrochem. Soc. 2006, 153, A1492.

[34] Y. Fu, Y. Jiang, S. Poizeau, A. Dutta, A. Mohanram, J. D. Pietras, M. Z. Bazant, J. Electrochem. Soc. 2015, 162, F613.

[35] C. R. Graves, J. Hjelm, Proc. $11^{\text {th }}$ European SOFC and SOE Forum 2014, Lucerne, Switzerland, 2014, pp. B1203.

[36] S. H. Jensen, A. Hauch, P. V. Hendriksen, M. Mogensen, N. Bonanos, T. Jacobsen, J. Electrochem. Soc. 2007, 154, B1325.

[37] R. Barfod, M. Mogensen, T. Klemens $\varnothing$, A. Hagen, Y. L. Liu, P. V. Hendriksen, J. Electrochem. Soc. 2007, 154, B371.

[38] E. P. Murray, T. Tsai, S. A. Barnett, Solid State lonics 1998, 110, 235.

[39] S. Primdahl, M. Mogensen, J. Electrochem. Soc. 1997, 144, 3409.

[40] S. P. Jiang, S. P. S. Badwal, Solid State lonics 1999, 123, 209.

[41] S. Primdahl, M. Mogensen, J. Electrochem. Soc. 1999, 146, 2827.

[42] R. R. Mosbæk, J. Hjelm, R. Barfod, J. Høgh, P. V. Hendriksen, Fuel Cells 2013, 13, 605.

[43] L. Uriati, M. Sc. Thesis, Universita di Bologna, Bologna, Italy, 2014.

[44] S. H. Jensen, A. Hauch, P. V. Hendriksen, M. Mogensen, J. Electrochem. Soc. 2009, 156, B757.

[45] J. Høgh, Ph.D. Thesis, Technical University of Denmark, Roskilde, Denmark, 2005.

[46] S. D. Ebbesen, M. B. Mogensen, International Patent, WO2013026555, 2013.

[47] S. H. Jensen, A. Hauch, P. V. Hendriksen, M. Mogensen, J. Electrochem. Soc. 2008,

[48] A. Hauch, S. H. Jensen, J. B. Bilde-Sørensen, M. Mogensen, J. Electrochem. Soc. 2007, 154, A619. 
[49] A. Hauch, M. Mogensen, Solid State lonics 2010, 181, 745.

[50] R. Kiebach, W. Zhang, W. Zhang, M. Chen, K. Norrman, H.-J. Wang, J. R. Bowen, R. Barfod, P. V. Hendriksen, J. Power Sources 2015, 283, 151.

[51] J.-P. Bonnet, F. Topin, L. Tadrist, Transp. Porous Media 2008, 73, 233.

\section{Figure Captions:}

Fig. 1 A) Test facility developed at DTU Energy for pressurized SOC stack testing. B) Outline of the test facility gas handling concept.

Fig. 2 A) $\Delta P$ across stack and heat exchangers as a function of the gas pressure. B) Temperature of the $\mathrm{N}_{2}$ inside the pressure vessel and stack temperature as function of gas pressure.

Fig. $3 \mathrm{iV}$ curves recorded with a 11-cell planar HTAS Delta stack at $750{ }^{\circ} \mathrm{C}$ w. air and $50 \% \mathrm{H}_{2}+50 \%$ $\mathrm{H}_{2} \mathrm{O}$.

Fig. 4 A) $O C V_{m}$ as function of stack pressure, and theoretical $O C V_{\text {th }}$ (thick line). Expressions for $\mathrm{OCV}_{\text {th }}$ and linear fit to $\mathrm{OCV}_{\mathrm{m}}$ vs. log are shown in the figure. B) $\mathrm{H}_{2} \mathrm{O}$ leak rates calculated from OCV measurements recorded between some of the iV curve measurements in Fig. 3. The OCV measurements were obtained with dry $\mathrm{H}_{2}+\mathrm{N}_{2}$ to the fuel electrodes and air to the air electrodes. C) Average Cell ASR calculated from the slope of the iV curves in Fig. 3 as function of stack pressure. The line is a power-law fit to the data points.

Fig. 5 A) Bode plot of the imaginary part of the average cell ASR, corrected for wiring inductance. The impedance was recorded at $750{ }^{\circ} \mathrm{C}$ and 1.2 bar. $\mathrm{H}_{2}$ balances the gas to the fuel-electrodes. The inset shows a Nyquist plot of the same spectra. B) Selected difference plots of some of the spectra in A. C) Bode plot of impedance spectra corrected for wiring inductance recorded from 1.2 to 25 bar at $750{ }^{\circ} \mathrm{C}, 50 \% \mathrm{H}_{2} \mathrm{O}+50 \% \mathrm{H}_{2}$ and air. Inset shows a Nyquist plot of the same spectra. D) Selected difference plots of some of the spectra shown in $\mathrm{C}$. The inset shows a magnification of the high-frequency part of the difference spectra. For simplicity 1.2 bar is denoted 1 bar in the legends.

Fig. 6 A) 200 h stack durability test showing stack voltage vs. time. Vertical columns indicate interruptions in constant current density operation. Time span during the interruptions are omitted in this graph. Current densities as well as voltage increase rates are indicated for each durability test segment. The main events during the interruptions are indicated with arrows and text. All interruptions were caused by safety system trigger events and test setup malfunctions. B) Cell OCV and ASR calculated from linear fits of cell iV curves similar to the stack iV curves in Fig. 3, obtained at three different instances: Before EL test, after a pressure and temperature cycle and after a steam starvation incident.

Fig. 7 Difference between theoretical OCV $\left(\mathrm{OCV}_{\text {th }}\right)$ and observed OCV $\left(O C V_{m}\right)$ per cell at ambient pressure, as function of the difference between the slope of the pressure-dependency of $\mathrm{OCV}_{\mathrm{m}}$ and $O C V_{\text {th. }}$. The value obtained in this work is compared to values reported in previous studies.

Fig. 8 A) Resistance and summit frequency $f_{s}$ for the gas concentration impedance obtained by modelling the imaginary part of the low-frequency arcs of the spectra in Fig. 5A (inset) using an (RC)-model. Power-law functions are subsequently fitted to the obtained data points. B) Electrode ASR calculated from Fig. $4 C$ minus a series resistance $\left(0.24 \Omega \mathrm{cm}^{2}\right)$ and a gas concentration resistance $\left(0.13 \Omega \mathrm{cm}^{2}\right)$. A power-law fit is applied to the electrode ASR and the equation is given in the figure. 
Figures:
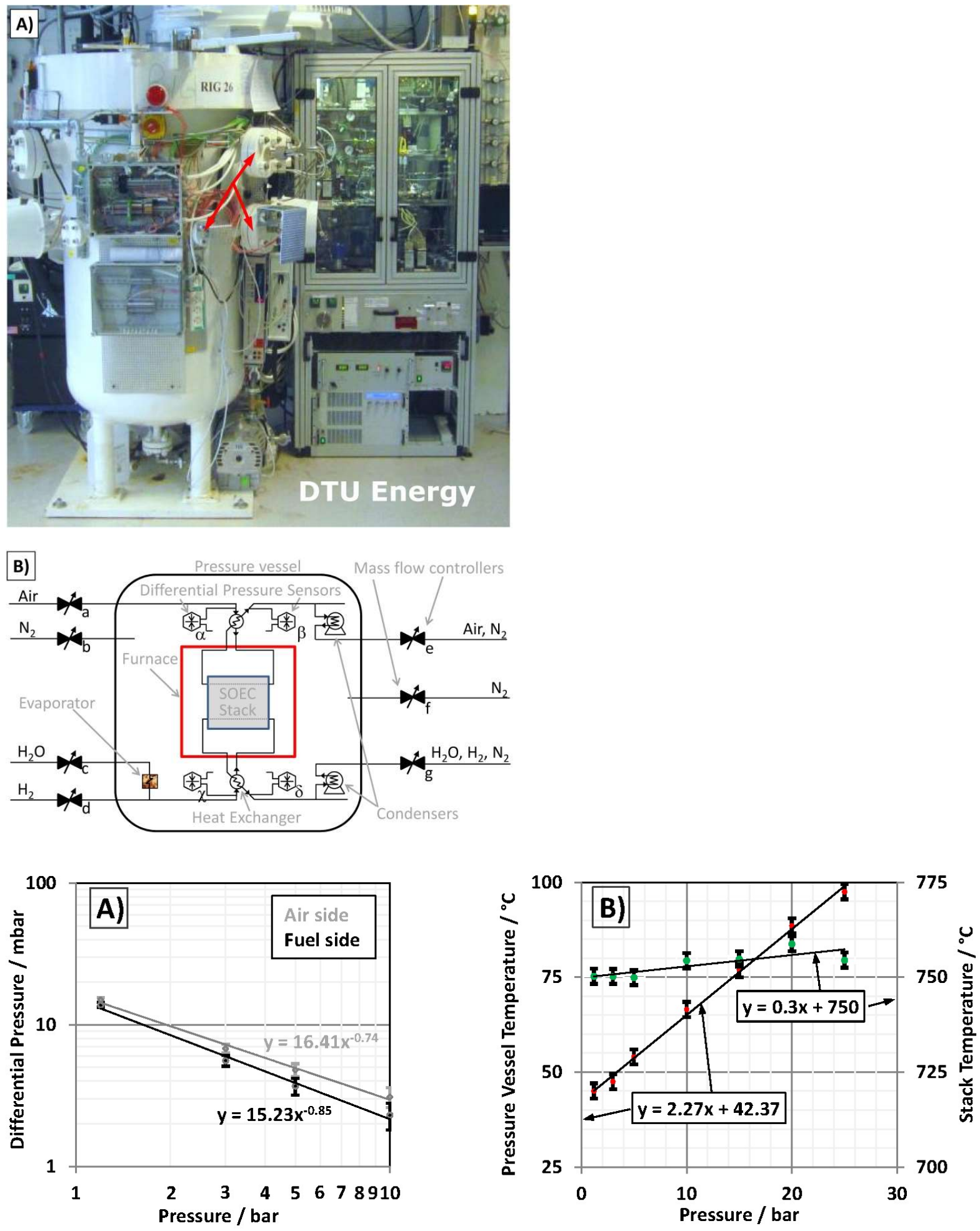

Page 22 

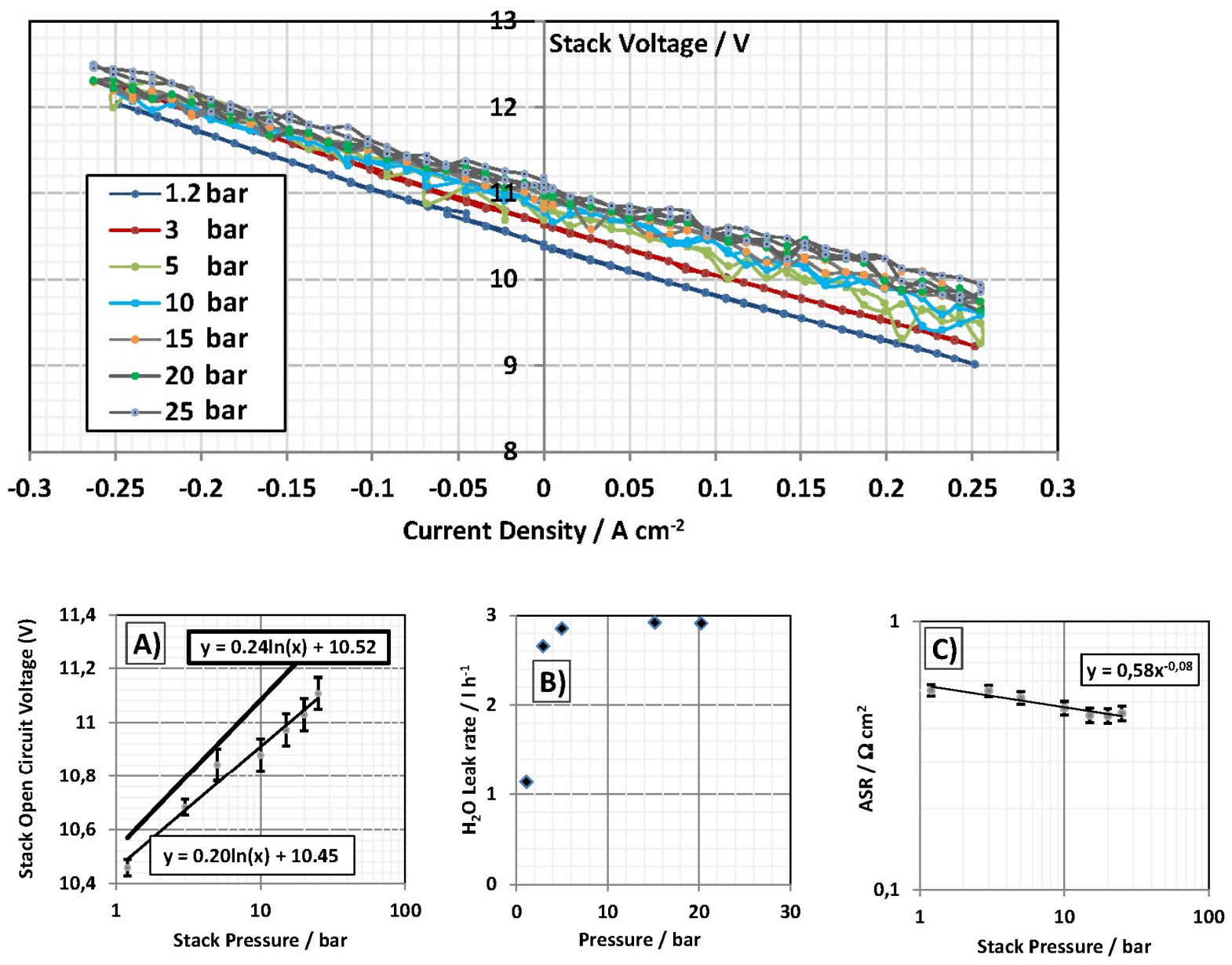

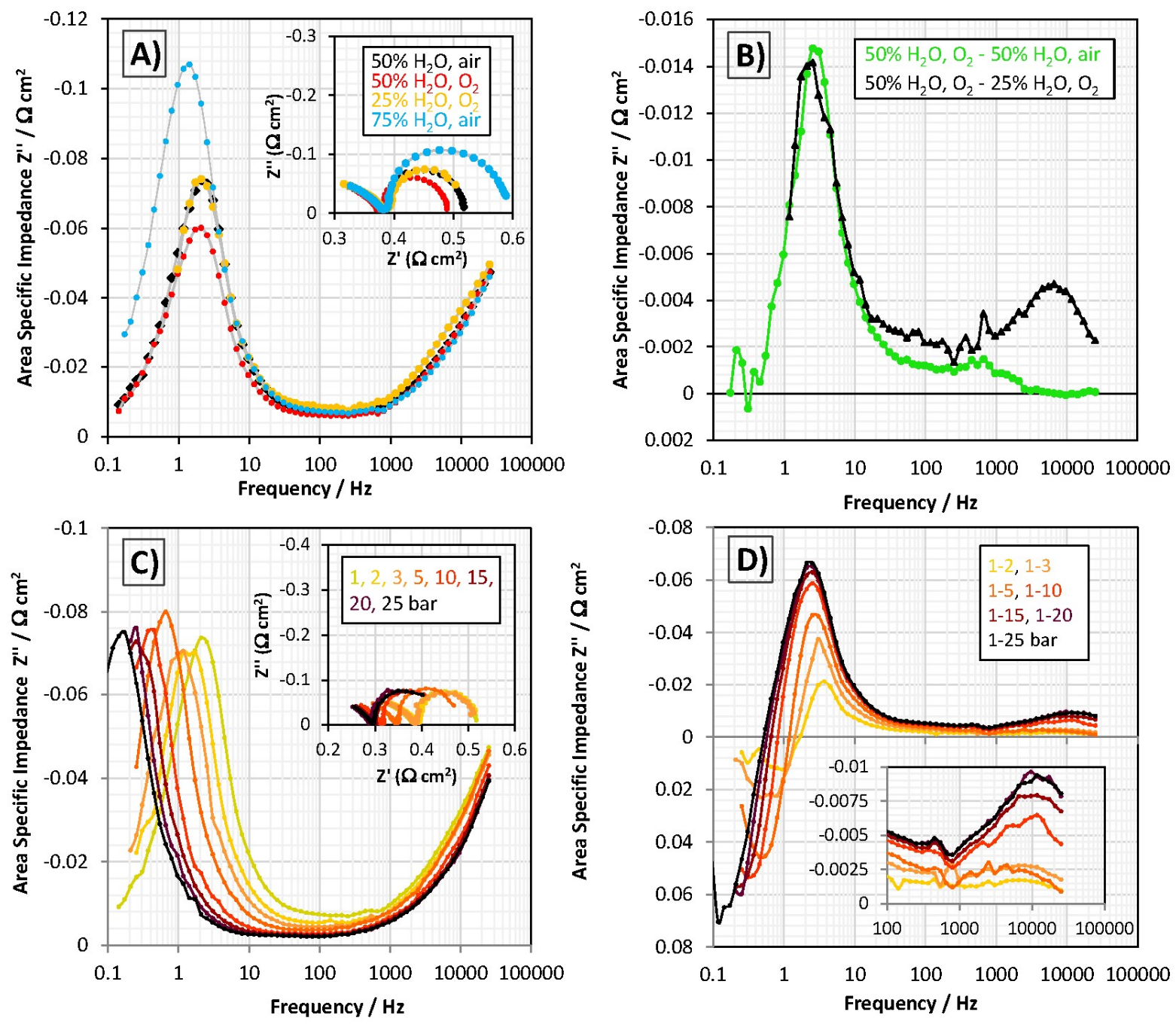

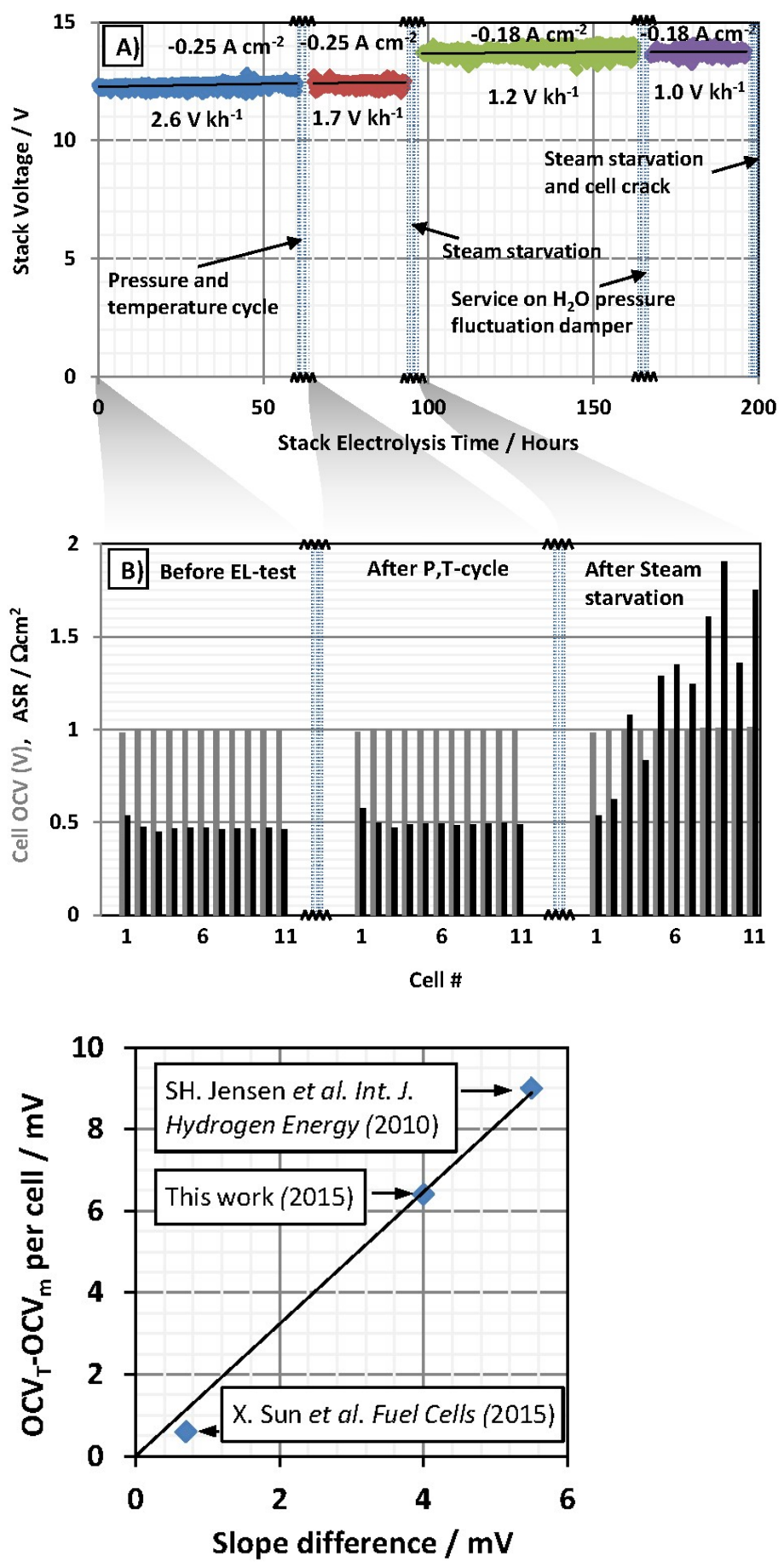

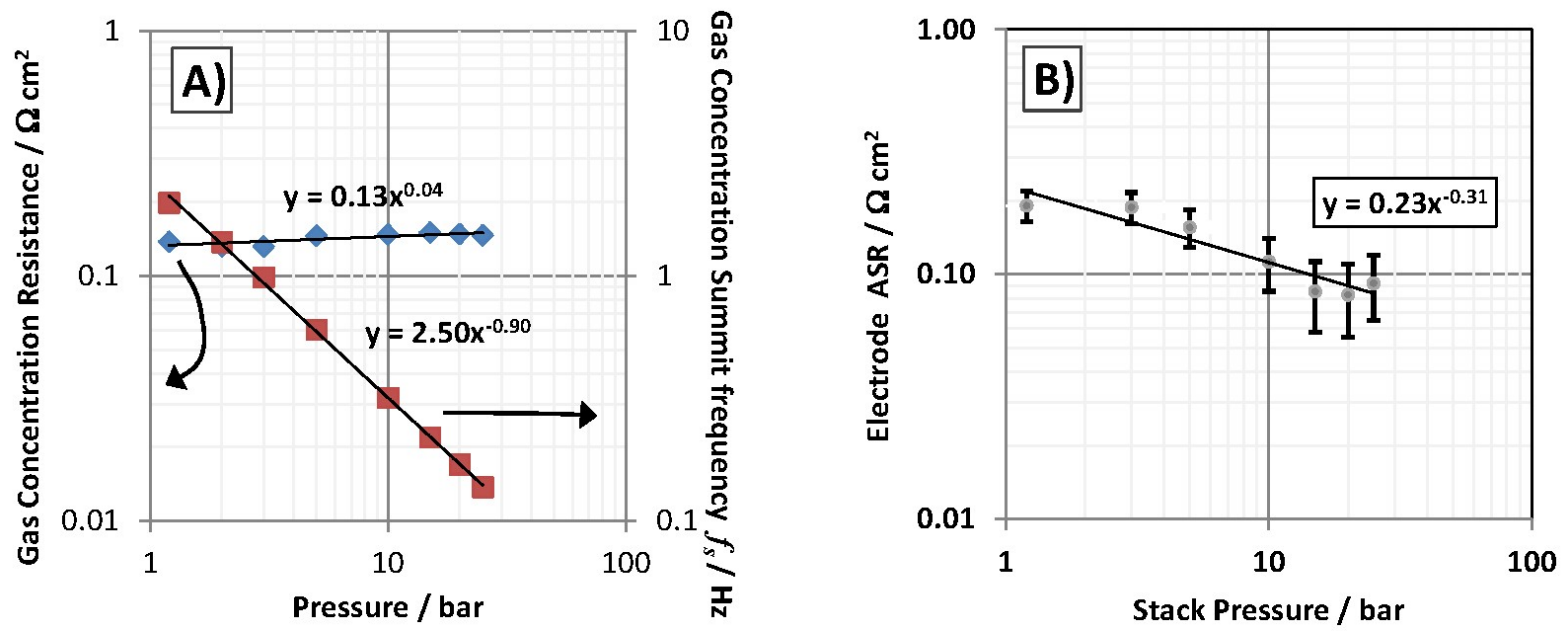

Page 26 